\title{
Aerosol Lidar and MODIS Satellite Comparisons for Future Aerosol Loading Forecast
}

\author{
Russell De Young $^{* a}$, James Szykman ${ }^{\mathrm{b}}$, Kurt Severance ${ }^{\mathrm{c}}$, D. Allen Chu ${ }^{\mathrm{d}}$, Rebecca Rosen ${ }^{\mathrm{e}}$, \\ Jassim Al-Saadi $^{\text {a }}$ \\ a Science Directorate, NASA Langley Research Center, MS401A, Hampton, Virginia 23681 \\ ${ }^{b}$ US Environmental Protection Agency, Office of Research and Development, National Exposure \\ Research Laboratory c/o NASA Langley Research Center, MS401A, Hampton, VA 23681 \\ ${ }^{c}$ Systems Engineering, NASA Langley Research Center, MS125, Hampton, VA, 23681 \\ ${ }^{\mathrm{d}}$ MODIS Aerosol Team, Joint Center for earth Systems Technology/NASA-Goddard Space Flight \\ Center Code 613.2, Climate and Radiation Branch, NASA Goddard Space Flight Center \\ Greenbelt, MD 20771 \\ ${ }^{\mathrm{e}}$ US Environmental Protection Agency, Region 9 (AIR-2) \\ 75 Hawthorne St., San Francisco, CA 94105 \\ ${ }^{a}$ Science Directorate, NASA Langley Research Center \\ MS401B, Hampton, VA 23681
}

\begin{abstract}
Knowledge of the concentration and distribution of atmospheric aerosols using both airborne lidar and satellite instruments is a field of active research. An aircraft based aerosol lidar has been used to study the distribution of atmospheric aerosols in the California Central Valley and eastern US coast. Concurrently, satellite aerosol retrievals, from the MODIS (Moderate Resolution Imaging Spectroradiometer) instrument aboard the Terra and Aqua satellites, were take over the Central Valley. The MODIS Level 2 aerosol data product provides retrieved ambient aerosol optical properties (e.g., optical depth (AOD) and size distribution) globally over ocean and land at a spatial resolution of $10 \mathrm{~km}$.

The Central Valley topography was overlaid with MODIS AOD ( $5 x 5 \mathrm{~km}^{2}$ resolution) and the aerosol scattering vertical profiles from a lidar flight. Backward air parcel trajectories for the lidar data show that air from the Pacific and northern part of the Central Valley converge confining the aerosols to the lower valley region and below the mixed layer. Below an altitude of $1 \mathrm{~km}$, the lidar aerosol and MODIS AOD exhibit good agreement. Both data sets indicate a high presence of aerosols near Bakersfield and the Tehachapi Mountains. These and other results to be presented indicate that the majority of the aerosols are below the mixed layer such that the MODIS AOD should correspond well with surface measurements. Lidar measurements will help interpret satellite AOD retrievals so that one day they can be used on a routine basis for prediction of boundary layer aerosol pollution events.
\end{abstract}

Keywords: aerosols, lidar, MODIS satellite, aerosol forecast

*russell.j.deyoung@nasa.gov; phone 757-864-1472. 


\section{INTRODUCTION}

Aerosols are of major importance due to there effect on human health and scattering and absorption of radiation resulting in climate change. Satellites such as Aura and Terra constantly measure the global aerosol optical depth (AOD) of the atmosphere, giving a quantitative measure of the aerosol loading over the Earth. Such satellite measurements have shown the global distribution of aerosols as a result of dust storms and biomass burning. While the utility of aerosol measurements on the global scale is well known the question arises, can satellite aerosol measurements be used to monitor aerosol concentrations on a regional basis? For example, could satellite aerosol measurements be used to monitor the air quality over major urban areas with sufficient accuracy to help sensitive population groups avoid exposure on an hourly or daily basis? The beginning of such an operational capability is available using the Air Now (www.airnow.gov) and the Infusing Satellite Data into Environmental Applications: IDEA (www.idea.ssec.wisc.edu) websites. The future goal would be to have similar sites for major cities or regional areas. This paper will describe efforts to measure AOD on a regional basis from Terra and Aura satellites and correlate these measurements with aerosol lidar measurements from both airborne and ground based lidars. These measurements can then be correlated with ground based $\mathrm{PM}_{2.5}$ measurements the result being a higher resolution temporal and spatial aerosol profile then is now available. These measurements are underway in two regional areas within the US, the Norfolk-Virginia Beach area and the California Central Valley. Recent aerosol measurement results from both these regions will be discussed in this paper.

\section{MODIS AEROSOL MEASUREMENTS}

The MODIS (Moderate Resolution Imaging Spectroradiometer) sensors on EOS-Terra MODIS launched in 1999 and on EOS-Aqua in 2002 were designed to systematically retrieve aerosol properties over both land and ocean [1, 2]. The success of MODIS aerosol retrieval is due to a unique set of seven well-calibrated channels $(0.47,0.55,0.67,0.87,1.24,1.64,2.1 \mu \mathrm{m})$ from visible to shortwave infrared wavelength. The MODIS-derived aerosol properties over land in tandem with those over ocean enable us to comprehensively study global aerosols [3].

The success of recent applications using MODIS aerosol products for studies of air quality [4-6] has demonstrated the value of satellite aerosol optical depth. Future operational satellite sensors such as Visible Infrared Imaging Radiometer Suite (VIIRS) and Geostationary Operational Environmental Satellite-R series (GOES-R) will provide aerosol measurements similar to MODIS. The current GOES imager is also capable of producing an aerosol optical depth product [7, 8]. VIIRS and GOES-R will provide new data sets for continued applications within air quality, allowing the use of these operational sensors to expand beyond traditional weather forecasting.

As important as sensor spectral sensitivity is in detecting aerosols, spatial resolution also plays a major role in correlating aerosol optical depth with particulate matter (PM) concentrations measured at the surface, provided that all aerosols reside within the boundary layer. Carried by winds, aerosols emitted from far away can be transported over oceans to different continents. The transcontinental mechanisms vary and are strongly dependent upon the season. Also evident and more frequently found in the US is smoke originated from forest fires from Central America to 
Canada. The aloft smoke layers may or may not be entrained into the boundary layer and thus raise difficulties in air quality monitoring using satellite sensors, such as MODIS. MODIS gives the atmospheric column AOD through the entire atmosphere but does not allow the vertical distribution to be resolved. Aerosol lidars are thus very useful, in combination with MODIS, giving the vertical profile of the aerosol concentration resulting in the observed AOD. Lidar can give the fraction of the AOD residing in the boundary layer which is correlated with ground PM measurements [9].

Figure 1 shows a plot of MODIS AOD correlated with a ground measurement of $\mathrm{PM}_{2.5}$ concentration during March 25 to May 14, 2006 for the Norfolk-Virginia Beach regional area. For this case the correlation of AOD with PM is reasonably good but there are times where there are significant differences. The difference could be related to aerosol layers outside the well mixed boundary layer and thus not measured by the ground station. Another difficulty is that this is the only PM ground station for this lager metropolitan area and thus does not represent the regional aerosol variability. MODIS has the capability of measuring AOD with pixels of 2x2 km giving a better representation of the region PM.

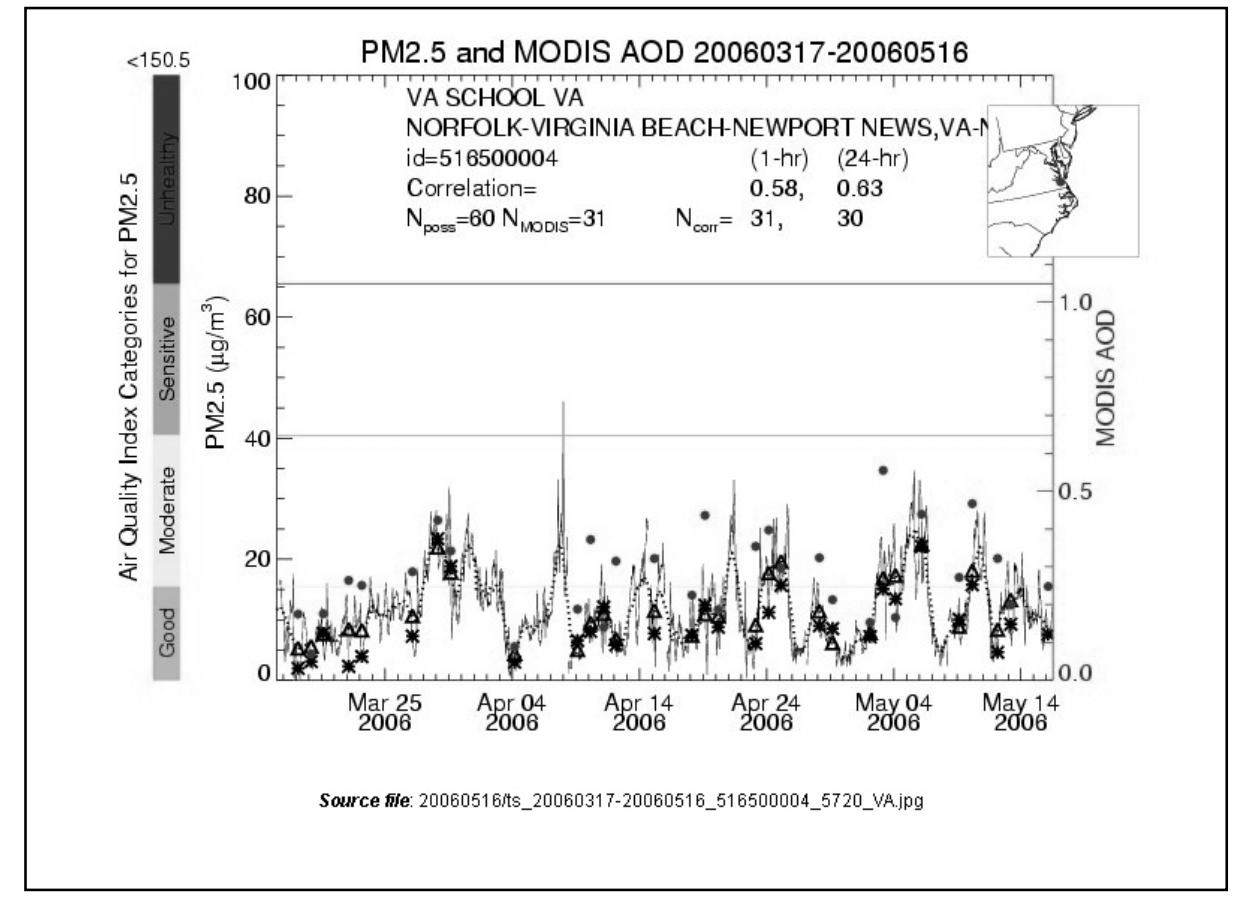

Fig. 1 Correlation between MODIS AOD and PN measures by a ground station in the NorfolkVirginia Beach regional area.

\section{LIDAR DATA PRESENTATION TECHNIQUE}

To better study the 3-D (three-dimensional) placement of the lidar aerosol profiles with respect to land topography, atmospheric backward trajectories, and MODIS aerosol optical depth data, an interactive computer visualization technique was developed. Each of these data components were 
transformed into 3-D graphics representations for simultaneous display in a standard Web browser. Within a 3-D latitude-longitude-altitude coordinate system, the user can interactively view a fullcolor lidar profile displayed over a 3-D high-resolution land map, and atmospheric backward trajectories can be observed intersecting the lidar profile and passing over the land masses. MODIS aerosol optical depth data acquired at approximately the same time as the lidar data can be overlaid as well.

To produce this 3-D visualization, custom software was developed to encode all the graphics into a standard format known as VRML97, also referred to as VRML2.0, which is a version of the Virtual Reality Modeling Language. A free plug-in, such as Cortona from ParallelGraphics, is used within the Web browser to view the result on most desktop PCs. The common technique of texture mapping, by which a raster image is aligned and mapped onto a set of 3-D polygons, is used extensively in this implementation, because it is an accelerated operation available on most graphics cards. Texture mapping is a very efficient approach to visualize very high resolution image-based data applied to true 3-D surfaces, such as lidar profiles and topographical maps.

An underlying 3-D topographical map was created by combining two main elements. The first element, resulting in the underlying mountain and valley terrain, was a public domain digital elevation model known as GTOPO30, accessible on the Web at http://edcdaac.usgs.gov/gtopo30/gtopo30.asp. This database, completed in 1996 by the U.S. Geological Survey's EROS Data Center, is a global digital elevation model with horizontal grid spacing up to 30 arc seconds (approximately $1 \mathrm{~km}$ ). Only one-fourth of this resolution, about 120 arc seconds, was necessary for the interactive visualization. The second element of the 3-D map was a large visible image to help identify key cities and land features. The public domain highresolution Landsat mosaic compiled by the NASA Jet Propulsion Laboratory at http://mapus.jpl.nasa.gov was the source of this image. This 2-D (two-dimensional) Landsat image was texture-mapped onto a subset of the 3-D GTOPO3D dataset and aligned in latitude and longitude to produce the final VRML97 3-D representation of the U.S. West Coast as a suitable landscape on top of which the lidar data could be visualized. One unit in the X-direction equals $1^{\circ}$ of longitude, a unit in the Y-direction equates to $1^{\circ}$ of latitude, and a unit in the Z-direction equals $50000 \mathrm{ft}$. Labels for major cities or other places of interest were added to the map as well. A similar map was created for Eastern Virginia and North Carolina, to visualize lidar flights on the U.S. East Coast.

The first step in overlaying the lidar data on this 3-D map is to create a mesh of polygons representing each flight profile. The top edge of this mesh is the path of the aircraft in 3-D latitude, longitude, and altitude coordinates, and the bottom edge is the projection of this path at sea level. (For display purposes, it is not necessary for every point in the flight to be represented in the mesh, so every 40th point in the flight path is used.) The set of 3-D points making up this mesh, and the order in which they are connected to finalize the mesh, were then encoded in VRML97 format. The second step to visualizing the data is to texture-map a high-resolution image of the lidar profiles onto the respective 3-D flight profile mesh. Since every vertical lidar profile was contained in a separate text file, every file from a flight was parsed to create a single image. A color scale was generated that indicated the intensity of the backscatter coefficient observed. Finally, the alignment of these image textures with the 3-D flight profiles described earlier was automatically encoded in 
VRML97 to produce the final 3-D visualization. Specific VRML97 constructs utilized to produce this 3-D texture mapping include IndexedFaceSet, IndexedLineSet, Coordinates, TextureCoordinates, and ImageTexture. The final component added to the visualization was air parcel backward trajectories starting in the lidar profile at 4000, 1000, and $0 \mathrm{~m}$ and going backward in time for $60 \mathrm{~h}$. After determining which backward trajectories best corresponded with a given flight, each trajectory was converted into a VRML97 representation. First, this conversion required adding the local elevation of the land from the GTOPO30 database, since each raw parcel altitude represented distance above the land surface. Then the parcel altitude was scaled to match the other visualization elements. Finally, all the points within a backward trajectory were connected by lines using the Extrusion and Spine constructs within VRML97.

MODIS aerosol optical depth data acquired at approximately the same time as the lidar data was also incorporated in the 3-D visualization. Each MODIS data point is represented as a square pixel placed just above the terrain map at the designated latitude and longitude. Six discrete colors are used to represent aerosol optical depth, and transparency is applied so that the terrain is visible underneath the MODIS data. The VRML97 IndexedFaceSet construct is used to represent each pixel of MODIS data.

\section{AIRBORNE AEROSOL MEASUREMENTS NORFOLK-VIRGINIA BEACH AREA}

An aerosol lidar (1064 nm) was deployed on a Lear Jet to measure the aerosol backscatter profile around the Norfolk-Virginia Beach regional area on August 1, 2005. Figure 2a shows the aerosol scattering ratio of this flight around this metropolitan area. While some clouds were encountered in the southern flight leg, most of the flight resulted in aerosol backscattering profile retrievals. Back trajectory analysis determined that the air mass was coming from the northeast. This allows the flux of aerosols to be determined and thus the transport of aerosols into and out of regional areas. Such analysis could help in regulatory statutes governing regional emissions.

Figure $2 \mathrm{~b}$ shows two sections of the flight one over the Chesapeake Bay and the other over the populated Newport News, VA area. The corresponding average aerosol scattering profiles are also shown indicating that the profile over land was influenced by anthropogenic aerosols. The winds were from the northeast so the Chesapeake Bay profile was not influenced by aerosols from land. This shows one example of the diversity of aerosol profiles within a regional area. In the future MODIS AOD data will be combined with lidar data to give a more complete picture of the regional aerosol distribution. These flights are in preparation for flights in the California Central Valley to map the aerosol distribution within the valley.

\section{MODIS AND AEROSOL LIDAR PROFILES IN THE CALIFORNIA CENTRAL VALLEY}

In the summer of 2003 several aerosol lidar flights were carried out in the California Central Valley showing the complex distribution of the valley aerosol distribution [10]. Figure 3a shows a 3-D projection of the Central Valley looking south toward the Tehachapi Mountains. On to this tropological projection is placed an airborne $1064 \mathrm{~nm}$ lidar aerosol scattering profile that give a snapshot of the aerosol distribution for 3 PM PST June 5, 2003. The darker the color, the higher the 
aerosol scattering ratio. Also shown in the figure are four aerosol scattering ratio plots for four different locations. Near Bakersfield, CA the scattering ratio is high as compared to the center of the valley. Also note that the peak of the ratio does not occur at ground but at about $1.5 \mathrm{~km}$. In this case MODIS would measure an AOD that would be inconsistent with a ground PM measurement as sometimes noted in Figure 1.

A first attempt was made to correlate MODIS AOD and aerosol lidar measurements in the Central Valley as shown in Figure 3b. Here MODIS AOD pixels of $5 x 5 \mathrm{~km}$ are projected over the valley during the time of an aerosol lidar flight showing the correlation of MODIS and lidar data. Both measurements show increased aerosols in the lower valley and seem to be generally consistent. The advantage of MODIS is its broad area coverage and daily measurement. The question remains as to where the aerosols are that MODIS is measuring. Future lidar flights are planned that will give greater insight into the how to interpret MODIS AOD data.

\section{CONCLUSIONS}

MODIS AOD data is very useful for global aerosol measurements but this paper addresses the ability of using MODIS data at higher resolution for regional aerosol air quality studies. Two examples, one in the Norfolk-Virginia Beach and another in the California Central Valley, have shown the utility of using aerosol lidar data to help interpret MODIS AOD data. MODIS with daily coverage over the whole U.S. could provide detailed air quality information for regional metropolitan areas.

\section{DISCLAIMER}

The views and opinions of these authors and organizations are not necessarily those of EPA. Scientists in EPA have prepared the EPA sections, and those sections have been reviewed in accordance with EPA's peer and administrative review policies and approved for presentation and publication.

\section{REFERENCES}

1. Kaufman, Y. J., D. Tanré, L. A. Remer, E. F. Vermote, D. A. Chu, and B. N. Holben, 1997: Operational remote sensing of tropospheric aerosol over the land from EOS-MODIS. J. Geophys. Res., 102, 17,051-17,061.

2. Tanré, D., Y. J. Kaufman, M. Herman, and S. Mattoo, 1997: Remote sensing of aerosol properties over oceans using the MODIS/EOS spectral radiances. J. Geophys. Res., 102, 16,97116,988 .

3. Chu, D. A., Y.J. Kaufman, G. Zibordi, J-D Chern, J-M Mao, and C. Li, H.B. Holben, 2003. Global Monitoring of Air Pollution over Land from EOS-Terra MODIS. J. Geophys. Res., 108(D21), 4661, doi: 10.1029/2002JD003179.

4. Wang, J., and S. A. Christopher, 2003: Intercomparison between satellite-derived aerosol optical thickness and PM2.5 mass: Implications for air quality studies. Geophys. Res. Lett., 30, doi:10.1029/2003GL018174. 
5. Engel-Cox, J.A., C.H. Holloman, B.W. Coutant, and R.M. Hoff, 2004. Qualitative and quantitative evaluation of MODIS satellite sensor data for regional and urban scale air quality. Atmos. Environ. 38, 2495-2509.

6. Al-Saadi, J., J. Szykman, B. Pierce, C. Kittaka, D. Neil, A. Chu, L. Remer, L. Gumley, E. Prins, L. Weinstock, C. MacDonald, R. Wayland, F. Dimmick, and J. Fishman, 2004. Improving national air quality forecasts with satellite aerosol observations. Bull. Am. Met. Soc., 86, 1249-1261, 2005.

7. Knapp, K. R., 2002: Quantification of aerosol signal in GOES visible imagery over the U.S., J. of Geophys. Res., 107.

8. Knapp. K., R. Frouin, S. Kondragunta, A. Prados, 2005: Toward aerosol optical depth retrieval over land using GOES visible radiances: determining surface reflectance, Int. Journal of Rem. Sens., in press.

9. Engel-Cox, J. A., R. M. Hoff, R. Rogers, F. Dimmick, A. C. Rush, J. J. Szykman, J. Al-Saadi, D. A. Chu, and E. R. Zell, 2006. Integrating Lidar and Satellite Optical Depth with Ambient Monitoring for 3-Dimensional Particulate Characterization, Atmos. Environ. (accepted).

10. De Young, R.J., W. Grant, K. Severance, “Aerosol transport in the California Central Valley observed by airborne lidar,” Environ. Sci. Technol. 39, 8351-8357, (2005). 

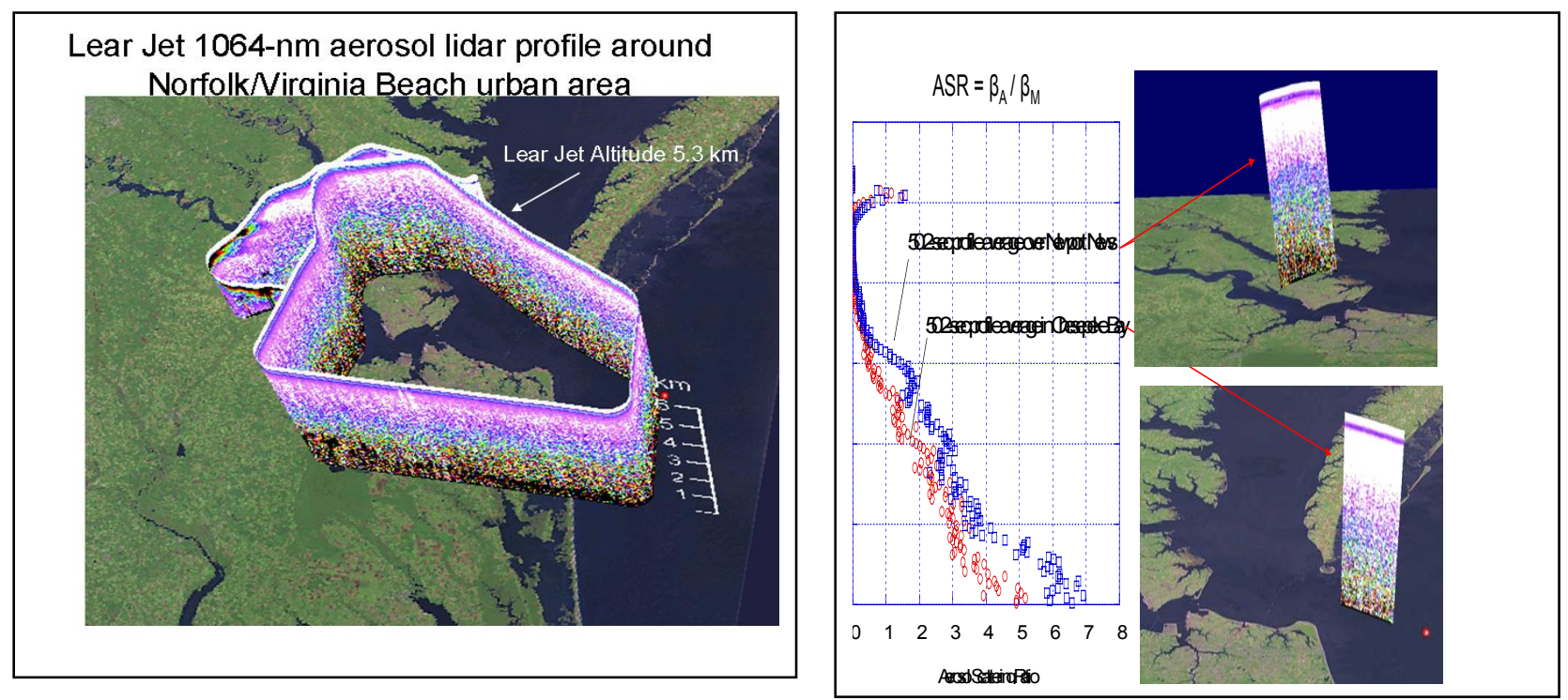

Fig. 2 a) Aerosol lidar flight around the Norfolk-Virginia Beach region. b) Aerosol scattering ratio profiles at $1064 \mathrm{~nm}$ for two different regional areas.
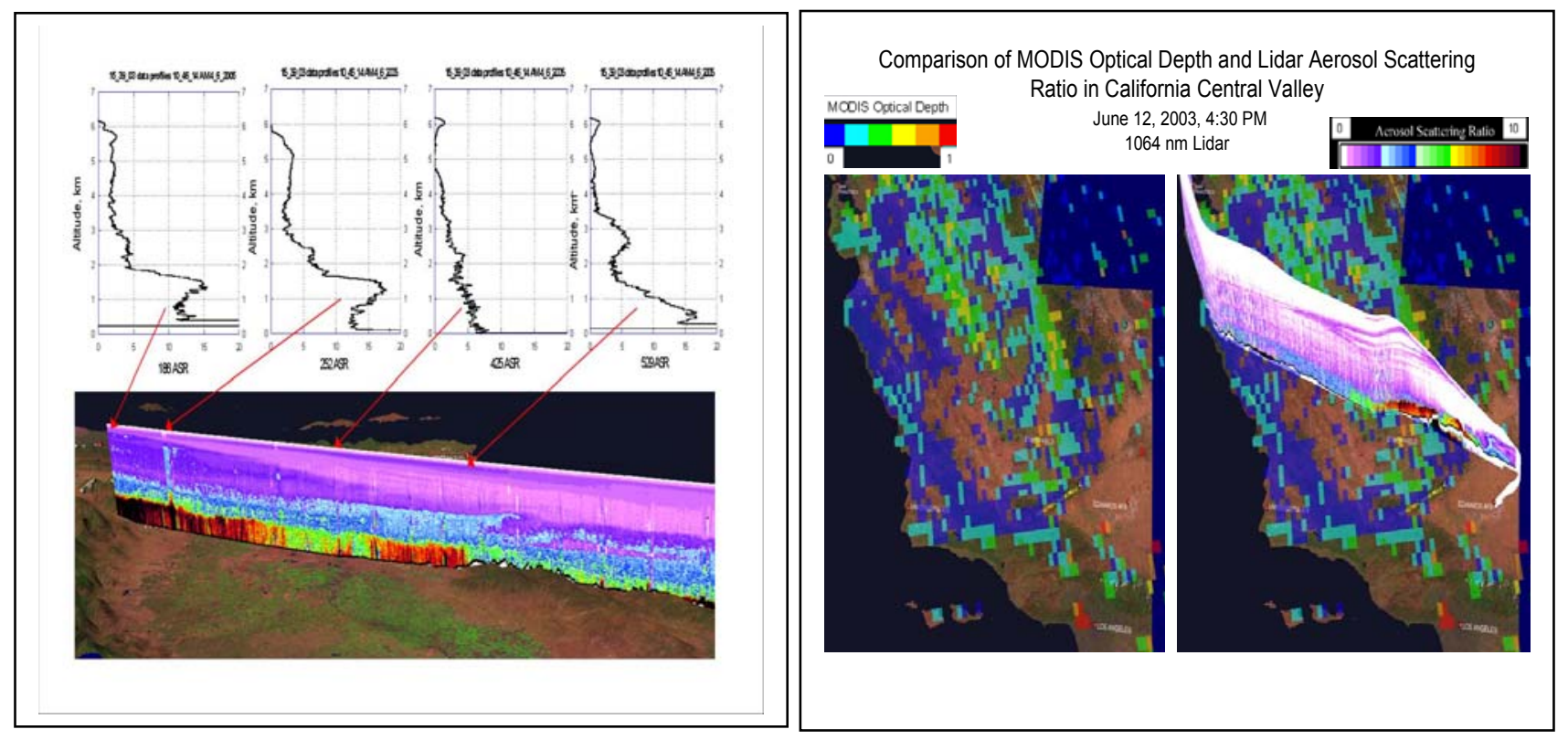

Fig. 3a) Aerosol lidar profile in the California Central Valley near Bakersfield with corresponding aerosol scattering ratios for different locations (1064 nm). b) A comparison of MODIS AOD and $1064 \mathrm{~nm}$ aerosol lidar profile. 